\title{
REHYDRATION OF OSMOTICALLY PRE-TREATED APPLE CUBES DRIED BY HOT AIR, MICROWAVE, AND FREEZE-DRYING
}

\author{
F.R. Assis, R.M.S.C. Morais and A.M.M.B. MoraIs* \\ Universidade Católica Portuguesa, CBQF - Centro de Biotecnologia e Química Fina - Laboratório Associado, \\ Escola Superior de Biotecnologia, Rua Arquiteto Lobão Vital, 172, 4200-374 Porto. Portugal
}

(Received: 27 September 2017; accepted: 21 December 2017)

Effects of the osmotic pre-treatment (OD) with sucrose or sorbitol solutions and different drying methods on the rehydration kinetics of apple cubes were studied. Samples were dried by hot air (HAD) at $70{ }^{\circ} \mathrm{C}$, by microwave (MWD) at $500 \mathrm{~W}$, and by freeze-drying (FD). The rehydration of dried samples was performed in water at $80{ }^{\circ} \mathrm{C}$ and at a mass ratio of sample to water of 1:100. The first order kinetic model was found to provide the best fit of the rehydration data. The pre-treatment and the drying method did not affect the rehydration kinetics, but the rehydration capacity after $12 \mathrm{~min}$ of rehydration was higher in the control samples than in the osmotically dehydrated ones, for all three drying methods. The rehydration rate and the rehydration capacity of the apple cubes dried by HAD, MWD, or FD were not affected by the solute used in the pre-treatment, sucrose and sorbitol.

Keywords: rehydration, cut apple, osmotic dehydration, hot air drying, microwave drying, freeze-drying

Normally, dried fruit are produced for consumption as final products with low moisture content, as powder or snacks. They may also be rehydrated to be used as food ingredients (intermediate moisture) in prepared products, or may also be rehydrated for other purposes (Contreras et al., 2012). The osmotic dehydration (OD) allows to preserve fruit by reducing the initial water content up to $50 \%$. The osmotic agent most used in the OD of fruit is sucrose, because of its effectiveness, convenience, and desirable flavour (LENART, 1996). Other solutes have been used in the osmotic process, such as sorbitol (CHAUHAN et al., 2011; RodRíGUEZ et al., 2013; BROCHIER et al., 2014). Sorbitol is a prebiotic with proven health benefits (CHAUHAN et al., 2011; Patel \& Goyal, 2012; Chandra \& Kumari, 2015). Besides, sorbitol is less caloric and has a relative sweetness of around $60 \%$ in comparison with sucrose (SILVEIRA \& JONAS, 2002).

The rehydration process aims to restore the properties of the fresh fruit by making the dried product contact with the rehydration solution (LEWICKI, 1998). During this process, transfer of water from the solution to the fruit and of soluble solids in the opposite direction takes place (SETTE et al., 2016). The quality of the rehydrated product depends on the structural and compositional changes occurring during the dehydration process (pre-treatment and/or subsequent drying) (LEWICKI, 1998; CONTRERAs et al., 2012).

Rehydration capacity is affected by tissue integrity and its hydrophilic properties (SETTE et al., 2016). This parameter, as well as the influence of factors such as the pre-treatment, drying method, and rehydration conditions on rehydration has been studied by many researchers. PEI and co-workers (2014) found that the rehydration rate of mushroom slices was higher at $70{ }^{\circ} \mathrm{C}$ than at $20^{\circ} \mathrm{C}$, but the opposite was observed for the equilibrium moisture

\footnotetext{
* To whom correspondence should be addressed.

Phone: +351-225580050; fax: +351-225090351; e-mail: abmorais@porto.ucp.pt
} 
content. MOREIRA and co-workers (2011) observed that the cells of chestnuts osmotically treated and dried with hot air at $65^{\circ} \mathrm{C}$ and, afterwards, rehydrated with water at $25^{\circ} \mathrm{C}$ swelled beyond the size of the fresh samples with just a short time of rehydration. Doymaz (2016) observed that the pre-treatment (citric acid and blanching) and the air temperature $\left(50-80^{\circ} \mathrm{C}\right)$ affected the rehydration of dried red kidney bean seeds. The rehydration ratio (mass of absorbed water: mass of dry matter) of the pre-treated samples was higher than the one of the control samples. MASKAN (2001) found that hot air-microwave dried slices of kiwifruit presented the highest and the microwave dried ones the lowest rehydration capacity.

Mathematical modelling may be performed to describe mass transfer kinetics during rehydration process, by using several empirical models and theoretical equations. NOSHAD and co-workers (2012) used five different models - Fick's second law of diffusion, Peleg's, Weibull's, first-order, and exponential association - to describe the rehydration kinetics of pre-treated air-dried quinces. These models confirmed a higher water absorption rate at higher temperature of rehydration and, in the beginning of the process, the rehydration of untreated samples was faster than the one of pre-treated samples. CONTRERAS and co-workers (2012) found that Peleg's model is an adequate tool to predict the rehydration behaviour of dried apple and apricot. They observed that microwaves applied during air drying resulted in a higher kinetic constant, which is related to the water absorption rate.

Dried apple cubes may be consumed as a snack or an ingredient in yoghurt, for example. Thus, the aim of this study was to evaluate the effect of the osmotic pre-treatment with sucrose or sorbitol combined with different drying methods - hot air, microwave, and freezedrying - on the rehydration kinetics of apple cubes.

\section{Materials and methods}

\subsection{Sample preparation}

Apples (Malus spp., cultivar Royal Gala) were graciously provided by Campotec, Portugal, and stored at $4{ }^{\circ} \mathrm{C}$. The fruit were washed and sanitized with aqueous solution with $7500 \mathrm{ppm}$ active chlorine for $5 \mathrm{~min}$. Then, the samples were cut in cubes $(12 \mathrm{~mm})$ with a vegetable cutter (Secret de Gourmet, France) and immersed in a solution with $0.9 \%$ sodium chloride for 3 min to prevent enzymatic browning. The samples were blotted gently with a tissue paper in order to remove the excess of sodium chloride solution from the surface. The soluble solids content of the apple was $15.3 \pm 1.3^{\circ} \mathrm{Bx}$ (Hand refractometer, Atago, China).

\subsection{Osmotic pre-treatment}

The osmotic solutions were prepared with ultra-pure water and commercial sucrose or sorbitol (Fagron Iberica, Spain) at $60^{\circ} \mathrm{Bx}$. The apple samples were immersed in the osmotic solution at a mass ratio of sample to solution of 1:4. The osmotic pre-treatment was carried out in beakers placed in a shaking incubator (SI-100C, Wiggenhauser, Germany). The experiments were carried out at atmospheric pressure and at $60{ }^{\circ} \mathrm{C}$, using constant agitation of 50 r.p.m. The experimental conditions had been optimized in a previous work (Assis et al., 2017a).

The samples (approximately $7 \mathrm{~g}$ ) were removed from the solution after 8 hours. Then, the samples were rinsed with ultra-pure water to remove the solution adhered to the surface and blotted with tissue paper in order to remove the excess of water from the surface. 


\subsection{Drying}

Hot air drying (HAD) experiments were performed in an oven (UFP800DW, Memmert, Germany) with recirculation of air with $9.5 \pm 1.3 \%$ relative humidity and at approximately $1 \mathrm{~m} \mathrm{~s}^{-1}$. The HAD experiments were carried out at $70^{\circ} \mathrm{C}$ for $3.5 \mathrm{~h}$. The experimental conditions had been optimized in a previous work (Assis et al., 2017b).

The microwave drying (MWD) experiments were performed in a domestic microwave oven (MT-243, Whirlpool, USA) at $500 \mathrm{~W}$ for 40, 27.5, and $25 \mathrm{~min}$ for the control and the samples osmotically dehydrated with sucrose solution or with sorbitol solution, respectively. The experimental conditions had been optimized in a previous work (Assis et al., 2017c).

For freeze-drying (FD), the samples were frozen at $-18{ }^{\circ} \mathrm{C}$ and then dried in a freezedryer with the condenser chamber at a temperature between -40 and $-45{ }^{\circ} \mathrm{C}$ (FT33A, Armfield, England) for $17 \mathrm{~h}$. The experimental conditions had been optimized in a previous work (Assis et al., 2018).

The control for all drying experiments was drying samples without the osmotic pretreatment.

The final water activity of the dried samples was aimed to be around 0.3 . Consequently, the final moisture content was $0.113 \pm 0.445,0.218 \pm 0.196$, and $0.103 \pm 0.035 \mathrm{~kg}$ water $/ \mathrm{kg} \mathrm{DM}$ after HAD, MWD, and FD, respectively.

\subsection{Rehydration experiments}

The rehydration experiments were carried out in beakers placed in a water bath at $80{ }^{\circ} \mathrm{C}$. The dried samples were immersed in ultra-pure water inside the beakers for 1, 3, 5, 9, and 12 min. The mass ratio of sample to water used was 1:100. After that time, the samples were removed and each side was blotted with tissue paper for $3 \mathrm{~s}$ to remove the excess of water from the surface. The samples were, then, weighed.

The moisture content of the rehydrated samples was determined in an oven (FP115, Binder, Tuttlingen, Germany) at $105^{\circ} \mathrm{C}$ until constant weight (Official Method 934.06, AOAC, 2002). The rehydration capacity (RC) was expressed as moisture content in kg water/ $\mathrm{kg}$ DM.

The experiments were conducted in triplicate.

\subsection{Mathematical modelling of the rehydration process}

To describe the rehydration kinetics of the dried apple cubes, mathematical models were used (Reyes et al., 2011; Noshad et al., 2012; Contreras et al., 2012).

The equations of the models are described below:

Peleg

$$
M=M_{0}+\frac{\mathrm{t}}{\mathrm{k}_{1}+\mathrm{k}_{2} \cdot \mathrm{t}}
$$

Weibull

$$
M=M_{\infty}+\left(M_{0}-M_{\infty}\right) \cdot \exp \left(-(t / B)^{\mathrm{A}}\right)
$$

First order kinetic

$$
M=M_{\infty}+\left(M_{0}-M_{\infty}\right) \cdot \exp (-k \cdot t)
$$

Exponential association equation

$$
M=M_{\infty} \cdot[(1-\exp (-H \cdot t)]
$$

where $M, M_{0}$, and $M_{\infty}$ are the moisture content at time $t$, at $t=0$, and at equilibrium, respectively. 


\subsection{Statistical analysis}

The statistical analysis was performed using Microsoft Excel 2000 (Microsoft Corporation, Washington, USA) (mean and standard deviation calculations) and IBM SPSS ${ }^{\circledR}$ Statistics 20.0 for Windows ${ }^{\circledR}$ (2012, SPSS Inc., Chicago, USA). The model parameters of the fit of the experimental data were estimated by non-linear regression procedures, and the margin of error of the estimates was calculated at $95 \%$ (the margin of error is the half width of the confidence interval at 95\%). The regressions were also assessed by ANOVA approaches and the significance level assumed was $5 \%$.

The adequacy of the model fit was evaluated by the determination coefficient $\left(\mathrm{R}^{2}\right)$ and by the residual analysis. The residual analysis was performed in order to check the assumptions of independence, randomness, and normality. The normality of the residuals was evaluated by Kolmogorov-Smirnov test.

\section{Results and discussion}

Peleg's, Weibull's, the first order kinetic, and the exponential association equation models presented high values of the determination coefficient $\left(\mathrm{R}^{2}\right)$ of the non-linear regression of the experimental data under all conditions, except for freeze-dried control samples. This was probably due to the variability of the experimental data. The residual analysis showed that the residuals of Peleg's and the first order kinetic models were normally distributed at a significance level of 5\%. The visual analysis of the scatterplot of the residuals vs. the predicted values indicates that the residuals are distributed randomly around zero with no systematic patterns, satisfying the assumption of homoscedasticity and zero mean errors. As an example, the residuals vs. the values predicted by the first order kinetic model used to fit the rehydration data of the freeze-dried control samples are presented in Figure 1. The other two models did not describe well the experimental data, because they did not follow one or more of the assumptions described above.

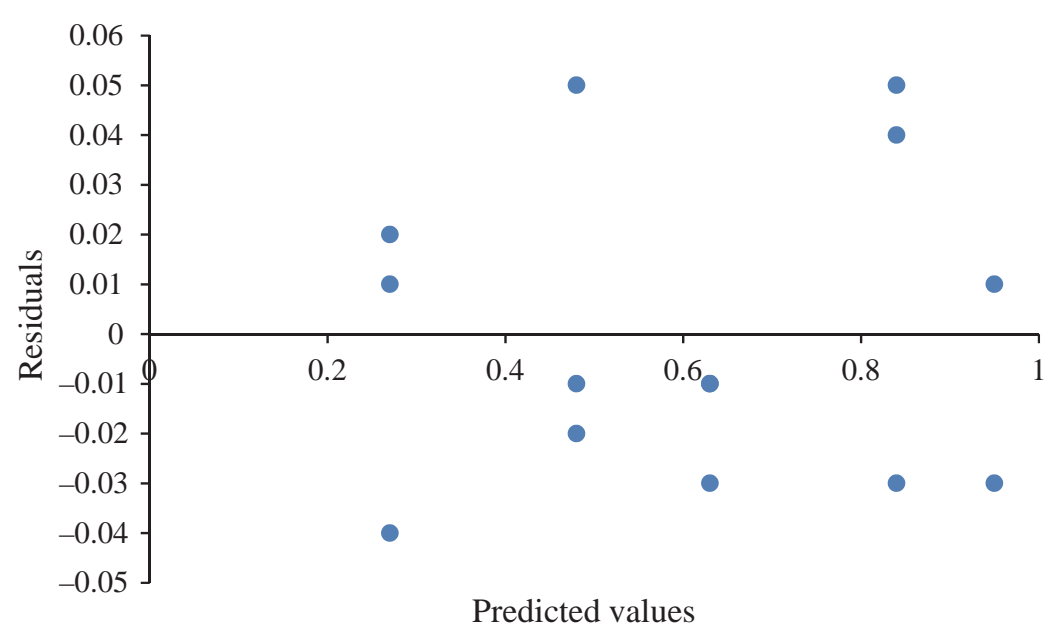

Fig. 1. Residuals vs. the values predicted by the first order kinetic model used to fit the rehydration data of the freeze-dried control samples 
In order to select the best fit of rehydration data, the Standard Half Width (SHW=margin of error/parameter value) was calculated at $95 \%$ confidence. The first order kinetic model presented the highest precision of parameter estimates (i.e., the lowest SHW) for all conditions used. So, it was used to compare the effect of these conditions. Figures 2 to 4 show the experimental data and the fit of the first order kinetic model during rehydration of the dried samples. The values of the parameters of the fit of the first order kinetic model, $k$ and $M_{\infty}$ (eq. 3 ), are presented in Table 1 . The $k$ parameter of this model is related to the rate of the rehydration. Thus, no significant differences were found among the rehydration rates ( $k$-values) of the different types of drying. Lin and co-workers (1998) dried blanched carrot slices by three different methods (vacuum microwave, hot air, and freeze-drying), and found that vacuum microwave drying resulted in the highest rehydration ratio. As observed by SETTE and co-workers (2016) in raspberries, the control freeze-dried samples (no pretreatment) showed a rapid increase in the rehydration coefficient (it represents the recovery degree of weight with respect to the reference fruit) and then remained constant over time. A similar behaviour was observed in the present work for the freeze-dried apple cubes without pre-treatment (freeze-dried control samples). After the first minute, rehydration was practically completed (Fig. 2).

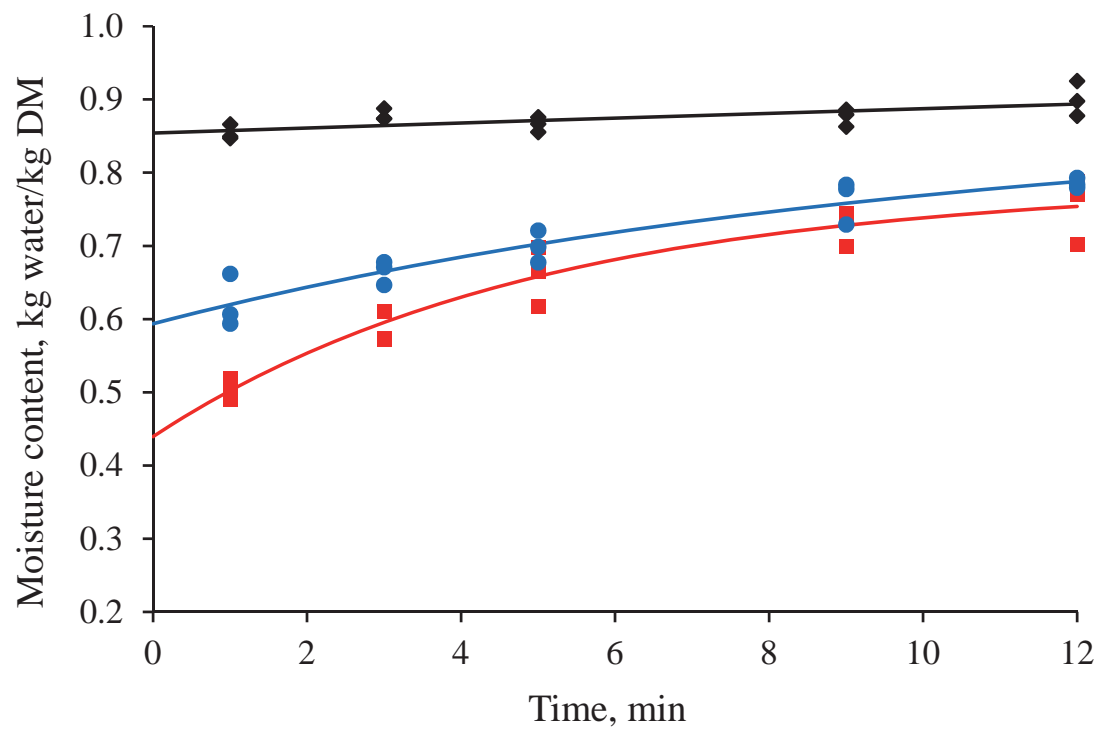

Fig. 2. Experimental data and fit of the first order kinetic model during rehydration of dried apple cubes : FD; $\mathbf{a}:$ HAD; $\odot$ : MWD; —: First order kinetic model

Based on the $k$-values of the first order kinetic model (Table 1), the osmotic dehydration carried out before each subsequent drying did not affect the rehydration rate of the dried samples. MALDONADO and co-workers (2010) also observed that mangoes osmotically pretreated with sucrose or glucose and air dried did not show any difference in the weight gain during rehydration compared to samples without pre-treatment. CicERZYNSKA and LENART (2010) and SETTE and co-workers (2016) observed a higher rehydration rate of the control samples than freeze-dried strawberries and raspberries pre-treated with sucrose and glucose, 
and sucrose, respectively. The equilibrium moisture contents, $M_{\infty}$, given by the first order kinetic model for hot air, microwave, and freeze-dried control samples are not significantly different, but tend to be higher than the respective osmotically dehydrated samples (Table 1), suggesting that the solute uptake that occurs during the pre-treatment reduces rehydration capacity. In fact, after 12 min of rehydration, the rehydration capacity (RC) of samples osmotically pre-treated with sucrose or sorbitol solutions (Figs 3 and 4, respectively) was similar, around $0.6 \mathrm{~kg}$ water $/ \mathrm{kg} \mathrm{DM}$, but it was lower than the $\mathrm{RC}$ of the respective control samples (Fig. 2). There were no significant differences in the rehydration rate ( $k$-values, Table 1) or RC (Figs 2 to 4 ) between the dried samples pre-treated with sucrose and sorbitol solutions.

Table 1. Parameters of the first order kinetic model fit of the rehydration capacity of dried apple cubes

\begin{tabular}{|c|c|c|c|c|}
\hline \multirow[t]{2}{*}{ Drying } & \multirow[t]{2}{*}{ Pre-treatment/ Solute } & \multicolumn{3}{|c|}{ First order kinetic } \\
\hline & & $\begin{array}{c}k \\
\left(\mathrm{~min}^{-1}\right)\end{array}$ & $\begin{array}{c}M_{\infty} \\
(\mathrm{kg} \text { water/kg DM) }\end{array}$ & $\mathrm{R}^{2}$ \\
\hline \multirow{3}{*}{ HAD } & Control & $0.200 \pm 0.143^{\mathrm{a}}$ & $0.785 \pm 0.082^{\mathrm{a}}$ & 0.926 \\
\hline & OD/sucrose & $0.182 \pm 0.035^{\mathrm{a}}$ & $0.689 \pm 0.032^{\mathrm{a}}$ & 0.995 \\
\hline & OD/sorbitol & $0.176 \pm 0.039^{\mathrm{a}}$ & $0.709 \pm 0.042^{\mathrm{a}}$ & 0.993 \\
\hline \multirow{3}{*}{ MWD } & Control & $0.098 \pm 0.141^{\mathrm{a}}$ & $0.875 \pm 0.223^{\text {a }}$ & 0.902 \\
\hline & $\mathrm{OD} /$ sucrose & $0.121 \pm 0.172^{\mathrm{a}}$ & $0.710 \pm 0.301^{\mathrm{a}}$ & 0.864 \\
\hline & OD/sorbitol & $0.196 \pm 0.102^{\mathrm{a}}$ & $0.671 \pm 0.072^{\mathrm{a}}$ & 0.954 \\
\hline \multirow{3}{*}{ FD } & Control & $0.014 \pm 0.474^{\mathrm{a}}$ & $1.106 \pm 7.641^{\mathrm{a}}$ & 0.464 \\
\hline & OD/sucrose & $0.161 \pm 0.073^{\mathrm{a}}$ & $0.664 \pm 0.070^{\mathrm{a}}$ & 0.974 \\
\hline & OD/sorbitol & $0.138 \pm 0.075^{\mathrm{a}}$ & $0.741 \pm 0.112^{\mathrm{a}}$ & 0.972 \\
\hline
\end{tabular}

The margin of error is the half width of the confidence interval at $95 \%$.

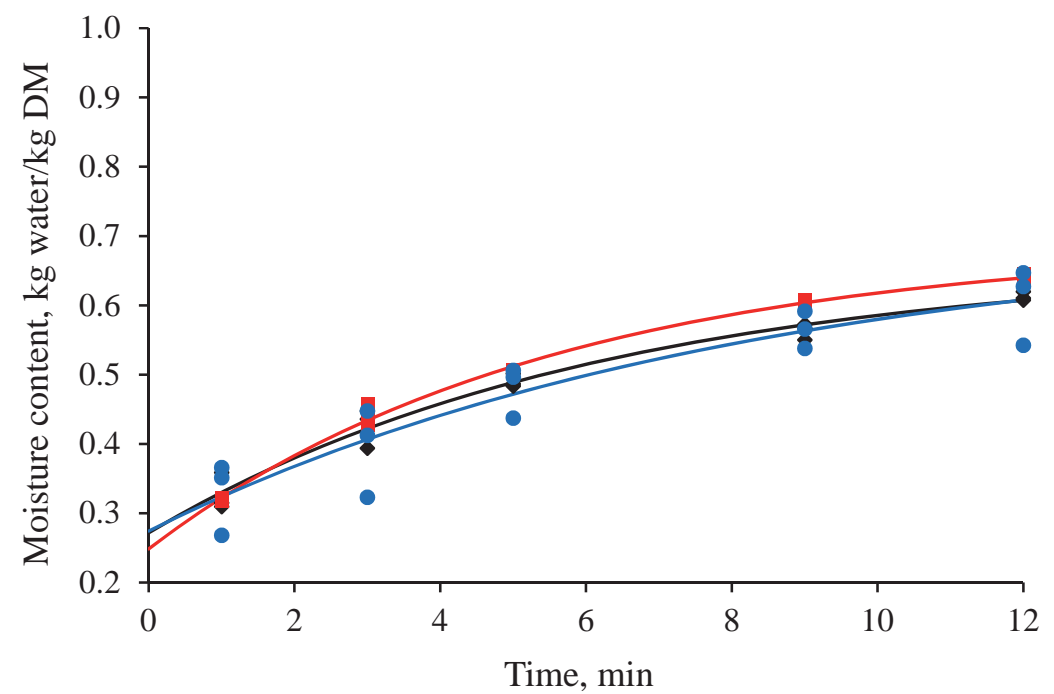

Fig. 3. Experimental data and the fit of the first order kinetic model during the rehydration of dried apple cubes osmotically pre-treated with sucrose solution

४: FD; $\mathbf{n}: \mathrm{HAD} ;$ : MWD; —: First order kinetic model 


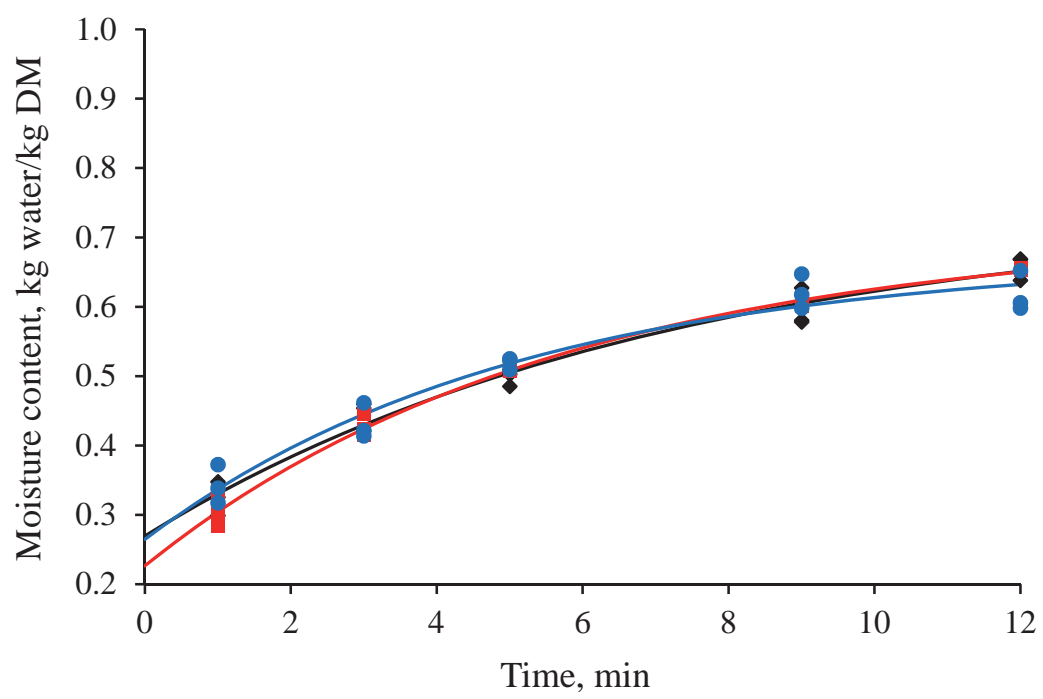

Fig. 4. Experimental data and the fit of the first order kinetic model during the rehydration of dried apple cubes osmotically pre-treated with sorbitol solution

४: FD; : HAD; : MWD; _: First order kinetic model

There was difference of rehydration behaviour among the freeze-dried control samples and the ones dried by the two other methods. In consequence, after 12 min of rehydration, the RC of the former was higher than the other two control samples (Fig. 2). This could be explained not only by the high porosity of freeze-dried samples, but also by the shrinkage of samples submitted to MWD and HAD, which makes the water adsorption more difficult. This difference was not noticed in osmotically dehydrated samples (Figs 3 and 4) probably due to the solute deposited in the surface layer. As explained by LenART (1996), in the initial stage of rehydration of this type of material, there occurs the dissolution of sugar in the surface layer, making the water adsorption inside the capillary-porous material difficult. Afterwards, in the course of the rehydration, the structure of the fruit determines the degree of rehydration, a certain amount of sugar leaking from the inside of the tissues. Therefore, there were no significant differences in the RC among the osmotically pre-treated samples dried by the three methods (Figs 3 and 4).

\section{Conclusions}

Among Peleg's, Weibull's, the first order kinetic, and the exponential association equation, the first order kinetic model was the most adequate to fit the rehydration kinetics of apple cubes osmotically pre-treated with sucrose or sorbitol and subsequently dried by hot air (HAD), microwave (MWD), or freeze-dying (FD). Neither the osmotic pre-treatment nor drying method affected rehydration rate. However, osmotic pre-treatment reduced rehydration capacity of apple cubes after all three drying methods at the end of $12 \mathrm{~min}$ of rehydration at $80^{\circ} \mathrm{C}$, which may be an important information for industrial application. The rehydration 
rate and rehydration capacity of the apple cubes dried by HAD, MWD, or FD were not affected by the solute used in the pre-treatment, sucrose and sorbitol.

Therefore, sorbitol is a good alternative to sucrose, as it presents several health benefits, because it is non-cariogenic, low-glycaemic and insulinaemic, and low-digestible.

\section{Abbreviations and nomenclature}

$\begin{array}{ll}\text { A, } B: & \text { Weibull's model parameters } \\ \text { DM: } & \text { dry matter } \\ \text { FD: } & \text { freeze-drying } \\ H: & \text { parameter of exponential association equation } \\ \text { HAD: } & \text { hot air drying } \\ k: & \text { parameter of first order kinetic model }\left(\mathrm{min}^{-1}\right) \\ k_{1}: & \text { Peleg's model parameter }(\mathrm{sg} \mathrm{DM} / \mathrm{kg} \mathrm{water}) \\ k_{2}: & \text { Peleg's model parameter }(\mathrm{kg} \mathrm{DM} / \mathrm{kg} \mathrm{water}) \\ M^{-1} & \text { moisture content at time } \mathrm{t}(\mathrm{kg} \mathrm{water} / \mathrm{kg} \mathrm{DM}) \\ M_{0}: & \text { initial moisture content }(\mathrm{kg} \mathrm{water} / \mathrm{kg} \mathrm{DM}) \\ M_{\infty}: & \text { moisture content at equilibrium }(\mathrm{kg} \mathrm{water} / \mathrm{kg} \mathrm{DM}) \\ \text { MWD: } & \text { microwave drying } \\ \text { OD: } & \text { osmotic dehydration } \\ \text { SHW: } & \text { standard half width } \\ t: & \text { time of rehydration (min) }\end{array}$

This work was supported by National Funds from FCT - Fundação para a Ciência e Tecnologia through project UID/ Multi/50016/2013. The first author acknowledges the financial support of CAPES (1528/13-0). The authors also acknowledge Campotec for graciously providing the apples for this study.

\section{References}

AOAC (2002). Official methods of analysis of AOAC International. $17^{\mathrm{TH}}$ ed. AOAC International, Gaithersburg, Md. USA

Assis, F.R., Morais, R.M.S.C. \& Morais, A.M.M.B. (2017a): Mathematical modelling of osmotic dehydration kinetics of apple cubes. J. Food Process. Pres., 41(3), doi:10.1111/jfpp.12895.

Assis, F.R., Morais, R.M.S.C. \& Morais, A.M.M.B. (2017b): Mathematical modelling of hot air convective drying of osmotically dehydrated apple cubes. J. Food Sci. Tech., 54, 3152-3160.

Assis, F.R., Morais, R.M.S.C. \& Morais, A.M.M.B. (2017c): Microwave drying of apple cubes - effect of the osmotic pre-treatment and comparison with hot air drying. Advances in Food Science and Engineering (AFSE), 1, 112-122.

Assis, F.R., Morais, R.M.S.C. \& Morais, A.M.M.B. (2018): Osmotic dehydration combined with freeze-drying of apple cubes and comparison with microwave drying and hot air drying. Advances in Food Science and Engineering (AFSE), 21 (1), 38-47.

BRochier, B., MarCZaK, L.D.F. \& Noreña, C.P.Z. (2014): Osmotic dehydration of yacon using glycerol and sorbitol as solutes: Water effective diffusivity evaluation. Food Bioprocess Tech., 8, 623-636.

Chandra, S. \& Kumari, D. (2015): Recent development in osmotic dehydration of fruit and vegetables: A review. Crit. Rev. Food Sci. Nutr., 55, 552-561.

Chaunan, O.P., Singh, A., Singh, A., Raju, P.S. \& Bawa, A.S. (2011): Effects of osmotic agents on colour, textural, structural, thermal, and sensory properties of apple slices. Int. J. Food Prop., 14, 1037-1048.

Cicerzynska, A. \& Lenart, A. (2010): Rehydration and sorption properties of osmotically pretreated freeze-dried strawberries. J. Food Eng., 97, 267-274.

Contreras, C., Martín-Esparza, M.E. \& Martínez-Navarrete, N. (2012): Influence of drying method on the rehydration properties of apricot and apple. J. Food Process Eng., 35, 178-190.

Doymaz, İ. (2016): Hot-air drying and rehydration characteristics of red kidney bean seeds. Chem. Eng. Commun., 203, 599-608. 
LenART, A. (1996): Osmo-convective drying of fruits and vegetables: Technology and application. Dry. Technol., 14, 391-413.

LEwICKI, P. (1998): Some remarks on rehydration of dried foods. J. Food Eng., 36, 81-87.

Lin, T.M.D., Durance, T. \& Scaman, C.H. (1998): Characterization of vacuum microwave, air and freeze dried carrot slices. Food Res. Int., 31, 111-117.

Maldonado, S., Arnau, E. \& Bertuzzi, M.A. (2010): Effect of temperature and pretreatment on water diffusion during rehydration of dehydrated mangoes. J. Food Eng., 96, 333-341.

MASKAN, M. (2001): Drying, shrinkage and rehydration characteristics of kiwifruits during hot air and microwave drying. J. Food Eng., 48, 177-182.

Moreira, R., Chenlo, F., Chaguri, L. \& Mayor, L. (2011): Analysis of chestnut cellular tissue during osmotic dehydration, air drying, and rehydration processes. Dry. Technol., 29, 10-18.

Noshad, M., Mohebbi, M., Shahidi, F. \& Mortazavi, S.A. (2012): Kinetic modeling of rehydration in air-dried quinces pretreated with osmotic dehydration and ultrasonic. J. Food Process. Pres., 36, 383-392.

Patel, S. \& Goyal, A. (2012): The current trends and future perspectives of prebiotics research: A review. 3 Biotech., 2, 115-125.

Pei, F., Shi, Y., GaO, X., Wu, F., Mariga, A.M., Yang, W., ... YAng, F. \& Hu, Q. (2014): Comparison of freeze-drying and freeze-drying combined with microwave vacuum drying methods on drying kinetics and rehydration characteristics of button mushroom (Agaricus bisporus) slices. Food Bioprocess Tech., 7, 1629-1639.

Reyes, A., Mahn, A. \& Huenulaf, P. (2011): Drying of apple slices in atmospheric and vacuum freeze dryer. Dry. Technol., 29, 1076-1089.

Rodríguez, M.M., Arballo, J.R., Campañone, L.A., Cocconi, M.B., Pagano, A.M. \& Mascheroni, R.H. (2013): Osmotic dehydration of nectarines: influence of the operating conditions and determination of the effective diffusion coefficients. Food Bioprocess Tech., 6, 2708-2720.

Sette, P., Salvatori, D. \& Schebor, C. (2016): Physical and mechanical properties of raspberries subjected to osmotic dehydration and further dehydration by air- and freeze-drying. Food Bioprod. Process., 100, 156171.

Silveira, M. \& Jonas, R. (2002): The biotechnological production of sorbitol. Appl. Microbiol. Biot., 59, 400-408. 